\title{
Ginsenoside CK induces apoptosis and suppresses proliferation and invasion of human osteosarcoma cells through the PI3K/mTOR/p70S6K1 pathway
}

\author{
KANG CHEN $^{1}$, JIANBAO JIAO ${ }^{1}$, JINWEI XUE ${ }^{1}$, TAOPING CHEN ${ }^{1}$, YU HOU ${ }^{1}$, YUANTAO JIANG ${ }^{1}$, \\ LIGANG QIAN $^{1}$, YUNFEI WANG ${ }^{1}$, ZHENG MA $^{1}$, ZHIXING LIANG $^{1}$, BO SUN $^{1}$ and QIAO REN ${ }^{2}$ \\ Departments of ${ }^{1}$ Orthopedics and ${ }^{2}$ Rheumatism and Immunology, \\ Affiliated Hospital of Hebei University, Baoding, Hebei 071000, P.R. China
}

Received June 21, 2019; Accepted December 4, 2019

DOI: $10.3892 /$ or.2020.7460

\begin{abstract}
Osteosarcoma is one of the most malignant bone tumors, and its major threats are aggressive invasion and early tumor metastasis, which result in a poor prognosis and high mortality. Accumulating evidence indicates that ginsenoside compound $\mathrm{K}(\mathrm{CK})$ has a significant antitumor effect, particularly on the inhibition of proliferation and invasion of numerous human tumors. In the present study, it was revealed that $\mathrm{CK}$ inhibited the viability and proliferation of osteosarcoma cells. Moreover, it was demonstrated that CK induced apoptosis and inhibited the migration and invasion of osteosarcoma cells via apoptotic staining, Annexin V/PI staining, and Transwell invasion assays. Furthermore, at the molecular level, the present results confirmed that apoptosis and invasion-related proteins were regulated by $\mathrm{CK}$, which was possibly related to the blockade of the PI3K/mTOR/p70S6K1 signaling pathway. In summary, the present findings indicated that CK inhibited viability and proliferation, induced apoptosis, and inhibited the migration and invasion of osteosarcoma cells through the $\mathrm{PI} 3 \mathrm{~K} / \mathrm{mTOR} / \mathrm{p} 70 \mathrm{~S} 6 \mathrm{~K} 1$ signaling pathway.
\end{abstract}

\section{Introduction}

Osteosarcoma mainly occurs in teenagers and healthy young patients, and is one of the most common fatal primary malignant bone tumors $(1,2)$, accounting for $5 \%$ of all pediatric tumors (3). The major threats of osteosarcoma are aggressive invasion and early multi-organ metastasis, especially pulmonary metastasis (4). Although survival has been greatly increased by surgical treatment combined with chemotherapy,

Correspondence to: Professor Qiao Ren, Department of Rheumatism and Immunology, Affiliated Hospital of Hebei University, 212 Yuhua East Road, Baoding, Hebei 071000, P.R. China E-mail: chkcmu@163.com

Key words: osteosarcoma, ginsenoside CK, proliferation, apoptosis, invasion the 5 year survival rate of patients with metastasis is still less than $35 \%$ (5). Therefore, the main strategy for the treatment of osteosarcoma is to block its invasiveness and metastasis to improve its prognosis. However, there are currently no effective drugs for osteosarcoma and the molecular mechanism remains obscure. Therefore, exploring targeted, highly effective treatments for osteosarcoma is urgently required.

The $\mathrm{PI} 3 \mathrm{~K} / \mathrm{mTOR} / \mathrm{p} 70 \mathrm{~S} 6 \mathrm{~K} 1$ pathway is an essential signaling pathway in cells, and has an extremely important biological function in cell growth, proliferation, apoptosis, angiogenesis and autophagy, as well as in other processes. Disorders of the pathway can cause a range of diseases, including cancer, neuropathy, and autoimmune diseases (6). The ribosomal 40S small subunit S6 protein kinase 1 (p70S6K1) is a direct substrate downstream of p-mTOR. P70S6K1 is phosphorylated by $\mathrm{p}$-mTOR to promote the production of ribosomes, initiation factors, and elongation factors in cells, and to promote proliferation and invasion of tumor cells $(7,8)$.

Ginsenoside compound K (20-O-D-glucopyranosyl20(S)-protopanaxadiol; CK; as shown in Fig. 1), is a major member of the original ginseng diol, saponins, and its study has been a popular research topic in the fields of anti-inflammatory and antitumor effects. Studies have revealed that ginsenoside $\mathrm{CK}$ is a compound with a variety of targets and pharmacological activities, which include anti-inflammatory (9), antitumor (10), anti-diabetic (11) and liver protection (12). However, to date, the antitumor mechanism of ginsenoside CK on osteosarcoma cells remains unclear. Therefore, in the present study, it was investigated whether CK exerted cellular antiproliferative effects and induced apoptosis in osteosarcoma cells. It was further explored whether the PI3K/mTOR/p70S6K1 signaling pathway played a decisive role in this process.

\section{Materials and methods}

Antibodies and reagents. Dulbecco's Modified Eagle's Medium (DMEM), high glucose medium, and fetal bovine serum (FBS) were obtained from Gibco; Thermo Fisher scientific, Inc. Human osteosarcoma cell lines, MG63 and U2-OS, were purchased from the Cell Bank of Shanghai Institutes for Biological Sciences. Ginsenoside CK (purity: >98\%) was 
purchased from Beijing Solarbio Science \& Technology Co., Ltd. MTT, dimethylsulfoxide (DMSO), and trypsin were purchased from Sigma-Aldrich; Merck KGaA. The acridine orange/ethidium bromide (AO/ET) staining kit was purchased from Beijing Solarbio Science \& Technology Co., Ltd. The BrdU cell proliferation kit was purchased from EMD Millipore. The TUNEL apoptosis kit was purchased from R\&D Systems. Matrigel was purchased from Collaborative Research, Inc. Transwell invasion chambers were purchased from Corning Costar. Rabbit antibodies to Bax (cat. no. ab32503), Bcl-2 (cat. no. ab182858), and caspase-3 (cat. no. ab2302) were purchased from Abcam. Rabbit antibodies to MMP-2 (cat. no. 10373-2-AP) and MMP-9 (cat. no. 10375-2-AP) were purchased from ProteinTech Group, Inc. Rabbit antibodies to PTEN (cat. no. 9188), serine/threonine kinase (Akt) (cat. no. 4691), phosphor-Akt (p-Akt) (cat. no. 4060), mTOR (cat. no. 2983), phosphor-mTOR (p-mTOR) (cat. no. 5536), and p70S6K1 (cat. no. 2708) were purchased from Cell Signaling Technology, Inc. RAD001 was purchased from Selleck Chemicals.

Cell culture. Human osteosarcoma cell lines, MG63 and U2-OS, were both cultured in DMEM high glucose medium containing $10 \% \mathrm{FBS}$ in a humidified incubator with $5 \% \mathrm{CO}_{2}$ at $37^{\circ} \mathrm{C}$. When the cells were $\sim 80 \%$ confluent, the cells were harvested with $0.25 \%$ trypsin plus $0.02 \%$ EDTA and subcultured. Both MG63 and U2-OS cells were divided into two groups: The negative control groups (NC groups) and the ginsenoside $\mathrm{CK}$ treatment groups (CK groups).

Cell proliferation analysis-MTT and BrdU. The viability of cells was evaluated by the MTT method. The two groups of osteosarcoma cells $\left(3 \times 10^{3}\right)$ were incubated in a 96-well plate for $24 \mathrm{~h}$, then the cells were treated with various concentrations of drugs (CK 0-30 $\mu \mathrm{M}$ or PBS), each concentration in parallel 6-wells. After both groups were incubated for 1-5 days, $20 \mu \mathrm{l}$ MTT solution was added to each well. After $4 \mathrm{~h}$, the medium was discarded and $150 \mu \mathrm{l}$ DMSO was added to dissolve the formazan crystals. The absorbance was measured using a wavelength of $490 \mathrm{~nm}$. The proliferation of cells was analyzed with a BrdU cell proliferation kit following the protocol of the manufacturer, similar to the aforementioned method, and the absorbance was measured at a wavelength of $450 \mathrm{~nm}$.

AO/EB apoptosis assay. Apoptosis-related morphological changes were detected using an AO/EB staining method. After treatment, both groups of cells were seeded on cover slides in a 24-well plate according to the manual, then $500 \mu \mathrm{l}$ of freshly-prepared dual stain containing $10 \mathrm{mg} / \mathrm{ml} \mathrm{AO}$ and $10 \mathrm{mg} / \mathrm{ml} \mathrm{EB}$ was added to each well to stain for $10 \mathrm{~min}$ in the dark at room temperature. The morphological changes of the cell nuclei were observed using a fluorescence microscope, and the apoptotic rate was calculated.

TUNEL apoptosis assay. A TUNEL apoptosis kit was used to further detect the morphological changes of the apoptotic nuclei. After induction of apoptosis, the cells were fixed in $4 \%$ paraformaldehyde for $30 \mathrm{~min}$, then PBS containing $0.3 \%$ Triton X-100 was added and incubated for $5 \mathrm{~min}$ at room temperature. After washing twice with PBS, $50 \mu 1$ of TUNEL assay solution and $20 \mu 1$ DAPI were added to each well of a 24-well plate and incubated at $37^{\circ} \mathrm{C}$ for $60 \mathrm{~min}$ in the dark. Then, the apoptotic nuclei were immediately observed using a fluorescence microscope, and the apoptotic rate was calculated.

Annexin V/PI apoptosis detection. Cell apoptosis was detected using an Annexin V/PI apoptosis detection kit according to the manufacturer's protocols. Briefly, after induction of apoptosis, the two cell types were harvested by trypsinization and washed twice in ice-cold PBS. The cells were centrifuged at $500 \mathrm{x} \mathrm{g}$ for $5 \mathrm{~min}$ and resuspended in $500 \mu \mathrm{l}$ binding buffer, then incubated with $5 \mu \mathrm{l}$ Annexin V-FITC and $10 \mu \mathrm{l}$ propidium iodide (PI) in the dark at room temperature for $15 \mathrm{~min}$. The samples were immediately analyzed using a FACSCalibur (BD Biosciences) flow cytometer and the data were analyzed using CellQuest software, version 5.1 (BD Biosciences).

Cell cycle analysis. After treatment with CK (0-30 $\mu \mathrm{M})$ for $24 \mathrm{~h}$, both groups of osteosarcoma cells were fixed in $70 \%$ ethanol for $24 \mathrm{~h}$ after washing twice with cold PBS at $4^{\circ} \mathrm{C}$ before analysis. After centrifugation $(1,000 \mathrm{~g})$, the cells were stained with $50 \mu \mathrm{g} / \mathrm{ml}$ PI and $100 \mu \mathrm{g} / \mathrm{ml} \mathrm{RNase}$ A for $30 \mathrm{~min}$ in the dark at room temperature. The samples were analyzed by a BD FACSCalibur flow cytometer and the CellQuest software was used to analyze the data.

Cell migration and invasion detection. The migration and invasive abilities of both groups of osteosarcoma cells were evaluated by Transwell migration and invasion systems. For the invasion assay, $20 \mu 1$ Matrigel was applied to cover the bottom of the chamber after being washed with serum-free medium to create a Matrigel membrane by incubating at $37^{\circ} \mathrm{C}$ for $30 \mathrm{~min}$. Cells $\left(5 \times 10^{4}\right)$ with $200 \mu \mathrm{l}$ of serum-free DMEM medium were seeded in the upper chamber of the Transwell system, and $500 \mu 1$ of DMEM high glucose medium containing 10\% FBS was added to the lower chamber as a chemoattractant. The Transwell system was incubated in a cell culture incubator for $24 \mathrm{~h}$, and then the upper chamber was removed and the cells from the upper surface of the membrane were removed. Then, the cells invading to the lower surface of the membrane were stained with $0.1 \%$ crystal violet for $5 \mathrm{~min}$ at room temperature and observed using an inverted phase-contrast microscope. The procedure for the migration assay was the same as above, but a Matrigel membrane was not required.

Western blot analysis. Cells were lysed in a radioimmunoprecipitation assay (RIPA) lysis buffer (Solarbio Science \& Technology) and the BCA method was used for protein determination. The protein samples from each group were resolved by SDS-PAGE and transferred to PVDF membranes (proteins were loaded by $50 \mathrm{ug} / \mathrm{lane}$ and the percentage of the gel was $10 \%$ ). After transfer, the PVDF membranes were blocked with $5 \%(\mathrm{w} / \mathrm{v})$ nonfat milk in TBST at room temperature for $2 \mathrm{~h}$, and then incubated with the primary antibodies $(1: 2,000)$ in TBST buffer containing $1 \%(\mathrm{w} / \mathrm{v}) \mathrm{BSA}$ at $4^{\circ} \mathrm{C}$ for $16 \mathrm{~h}$. Following three washes in TBST, the membranes were incubated with the appropriate HRP-linked secondary antibody (goat anti-rabbit 1:1,000; cat. no. SA00001-2; ProteinTech Group) in TBST for $2 \mathrm{~h}$ at room temperature. Proteins were detected by an ECL system (GE Healthcare). 


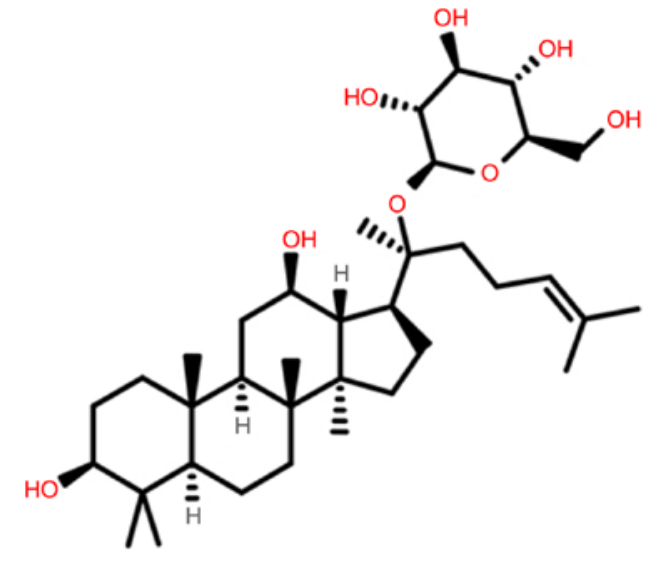

Figure 1. The chemical structure of CK. CK, ginsenoside compound K.

Statistical analysis. All statistical analyses were performed with one-way analysis of variance (ANOVA) and Newman-Keuls post hoc test using SPSS statistical software for Windows, version 13.0 (SPSS, Inc.), and GraphPad Prism 6 software (GraphPad Software, Inc.) was used to draw statistical charts. Data are presented as the mean \pm SEM from a minimum of three independent experiments performed in triplicate. Differences with $\mathrm{P}<0.05$ were considered to indicate a statistically significant difference.

\section{Results}

$C K$ inhibits the viability and proliferation and induces $G 2 / M$ arrest of osteosarcoma cells. The MTT assay revealed that there was no significant difference in cell viability between the CK and normal control (NC) groups of MG-63 and U2-OS cells on days 0-2 after drug treatment ( $>0.05)$. However, after 3 days, CK exhibited significant inhibition of viability and proliferation against MG-63 and U2-OS cells $(\mathrm{P}<0.05)$ in a time-dependent manner (Fig. 2A). Cells were treated with different concentrations of CK $(0,5,10,15,20,25$ and $30 \mu \mathrm{M})$. The $\mathrm{IC}_{50}$ value for $72 \mathrm{~h}$ was $\sim 20 \mu \mathrm{M}$, which was used as the effective drug concentration in subsequent experiments (Fig. 2A). The results of the BrdU assay further confirmed this conclusion; cells in the CK group exhibited significant inhibition of viability, and at the same drug concentration $(20 \mu \mathrm{M})$, the inhibition of MG-63 viability was more pronounced than that of U2-OS cells (Fig. 2B). Furthermore, it was also revealed that compared to the control group, cells in the CK group exhibited G2/M-phase cell cycle arrest, which was possibly related to cell proliferation and apoptosis (Fig. 2C and D).

Apoptotic changes of cell nuclei dual-stained with AO/EB. The abovementioned results confirmed that $\mathrm{CK}$ inhibited the viability and proliferation of osteosarcoma cells. To further analyze the apoptosis induction effect of CK in MG-63 and U2-OS cells, AO/EB nuclear staining was performed to observe the morphological changes of apoptotic nuclei. As revealed in Fig. 3A and B, when cells were treated with CK $(20 \mu \mathrm{M})$, MG-63 and U2-OS cells exhibited different degrees of apoptosis. Based on analyses of the histograms in Fig. 3, the apoptosis rates in the CK groups (MG-63, 24.16 $\pm 2.25 \%$; U2-OS, $17.66 \pm 1.37 \%$ ) were significantly higher than those in the NC groups (MG-63, 3.34 $\pm 1.16 \%$; U2-OS, $1.65 \pm 0.84 \%$ ) $(\mathrm{P}<0.05)$.

CK induces apoptosis of osteosarcoma cells detected by TUNEL assays. A TUNEL apoptosis kit was used to further detect the morphological changes of apoptotic nuclei. As revealed in Fig. 4, in the MG-63 group, the apoptosis rate of the NC group was only $1.52 \pm 0.63 \%$, and the value increased to $25.33 \pm 2.68 \%$ after treatment with CK $(20 \mu \mathrm{M})$. Similar results were also obtained in the U2-OS group $[0.45 \pm 0.22 \%$ vs. $24.83 \pm 1.92 \%$ (NC group)]. These results indicated that CK induced apoptosis in both MG-63 and U2-OS cells.

CK induces apoptosis in osteosarcoma cells. The Annexin V/propidium iodide (PI) staining assay was employed to further confirm the apoptotic effect of CK. As revealed in Fig. 5A and B, after treatment with CK, the percentage of apoptosis in MG-63 and U2-OS cells in the experimental group was significantly higher than that in the control group $(\mathrm{P}<0.05)$. In the MG-63 group, both early apoptosis $(5.42 \pm 1.90 \%)$ and late apoptosis $(16.71 \pm 1.65 \%)$ were higher than that in the control groups $(3.32 \pm 0.85$ and $5.83 \pm 1.08 \%$, respectively), and the total apoptosis was more pronounced ( $22.17 \pm 2.45$ vs. $9.15 \pm 1.85 \%)$. U2-OS cells revealed a similar result ( $9.74 \pm 2.20$ vs. $3.59 \pm 2.17 \%$ for total apoptosis). To validate the aforementioned conclusions at the cellular pathway level, the expression levels of apoptosis-related proteins were detected by western blot analyses. As revealed in Fig. 5, compared with the control group, the expression levels of the proapoptotic proteins cleaved caspase-3 and BAX were significantly upregulated in the CK group in MG-63 and U2-OS cells, while the expression of the inhibitory protein, Bcl-2, was downregulated $(\mathrm{P}<0.05)$. From the aforementioned results, it was concluded that CK significantly induced apoptosis in osteosarcoma cells.

CK inhibits the migration and invasion of osteosarcoma cells. In the previous results, it was demonstrated that CK inhibited proliferation and induced apoptosis of osteosarcoma cells. To further confirm the effect of $\mathrm{CK}$ on the migration and invasion of osteosarcoma cells, a Transwell assay was used. As revealed in Fig. 6A, the number of cells in the CK group passing through the Transwell chamber membrane were significantly lower in the MG-63 and U2-OS CK-treated groups than in the control group [invasion: MG63, $75.72 \pm 19.13$ vs. $318.16 \pm 26.37$ (control), $\mathrm{P}<0.05$; U2-OS, $45.83 \pm 14.22$ vs. $362.37 \pm 21.71$ (control), $\mathrm{P}<0.05$; migration: MG63, $123.15 \pm 12.39$ vs. $398.63 \pm 31.40$ (control), $\mathrm{P}<0.05$; U2-OS, $132.94 \pm 29.91$ vs. $453.33 \pm 34.17$ (control), $\mathrm{P}<0.05$ ], indicating that $\mathrm{CK}$ inhibited both the migration and invasion of MG-63 and U2-OS cells. To further characterize the relationship between CK and the mTOR signaling pathway, RAD001, a specific inhibitor of mTOR, was added. As revealed in Fig. 6B, the number of cells in the CK or RAD001 group passing through the Transwell chamber membrane was significantly lower than in the NC group, and this trend was more pronounced when cells were treated with both CK and RAD001. Therefore, it was hypothesized that CK played a similar role as an mTOR inhibitor, and that this effect was related to the mTOR signaling pathway. Furthermore, the expression of the invasion-related proteins, 

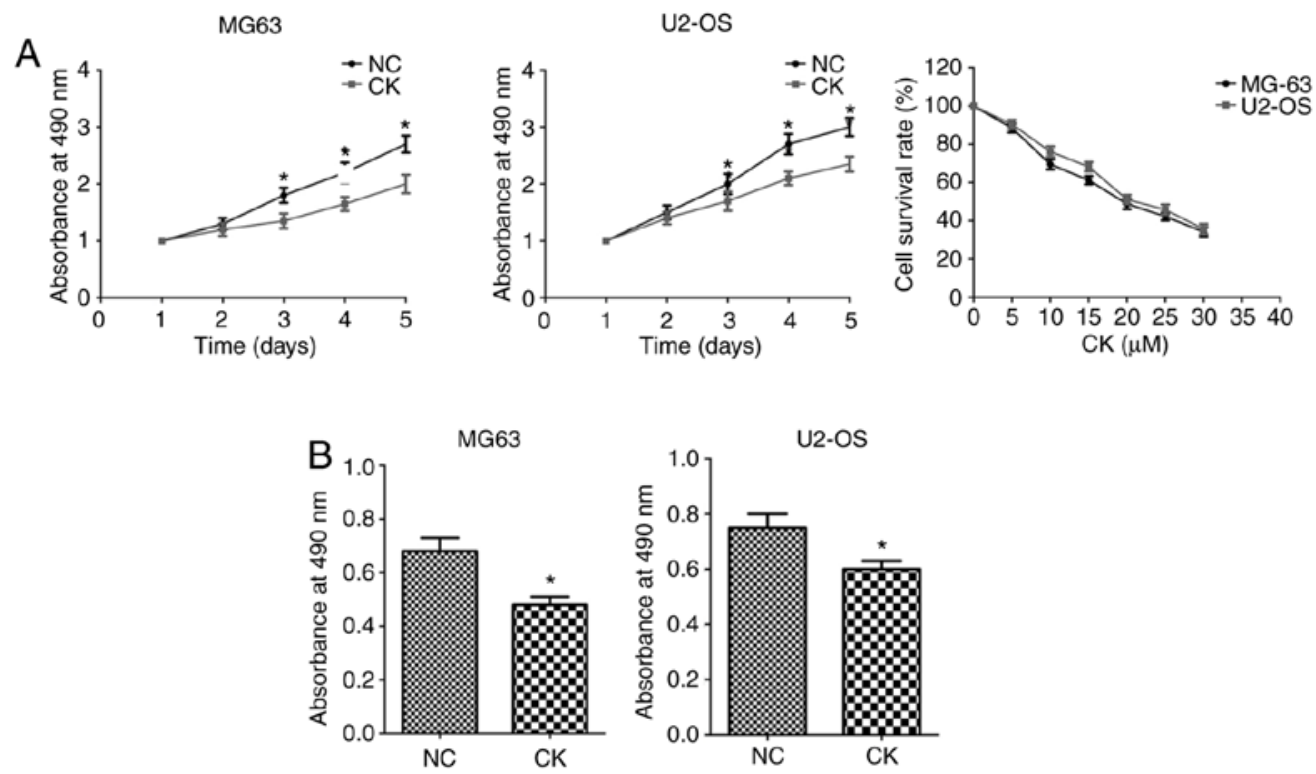

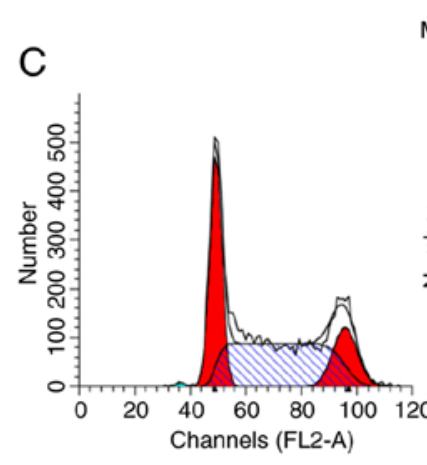

NC

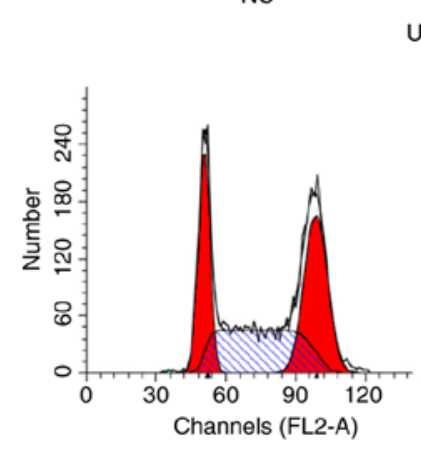

NC

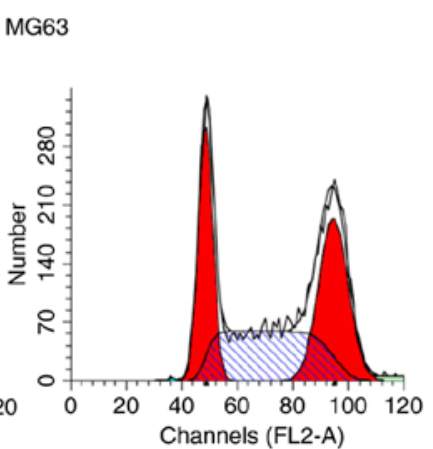

CK

U2-OS

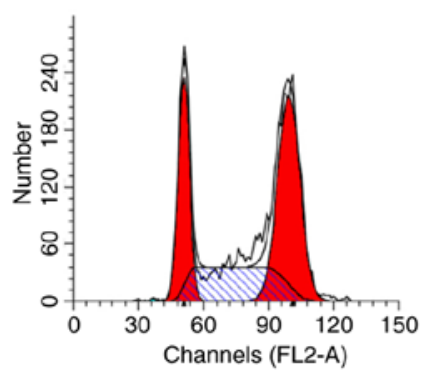

CK

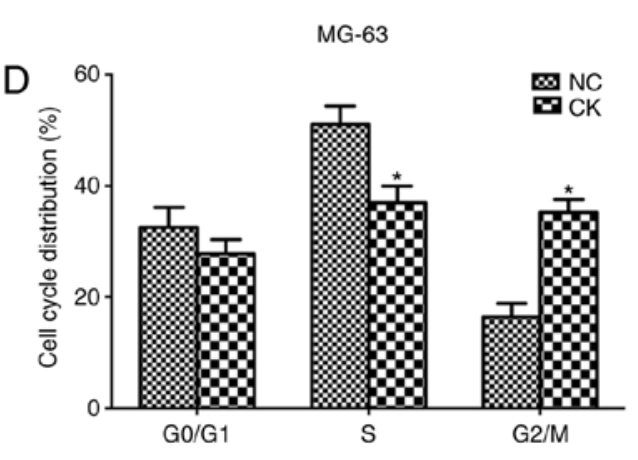

Figure 2. CK inhibits viability and proliferation of MG63 and U2-OS cells. (A) Cells were treated with different concentrations of CK (0, 5, 10, 15, 20, 25 and $30 \mu \mathrm{M}$ ). CK exhibited significant inhibitory effects on MG63 and U2-OS cells, as revealed by MTT assay. (B) BrdU cell proliferation kits were used to evaluate the anti-proliferation effect of CK on MG63 and U2-OS cells. (C) Propidium iodide staining cell cycle analyses were performed to detect the distribution of cells at each state of the cell cycle following CK treatment. (D) Cell cycle distribution of CK-treated cells revealed G2/M-phase arrest. * $<0.05$ vs. the NC group. Experiments were repeated three times and the results are expressed as the mean \pm SEM. CK, ginsenoside compound K; NC, normal control.

MMP-2 and MMP-9 were detected, in each group by western blot analyses. As indicated in Fig. 6C, the results revealed that after treatment with CK, MMP-2 and MMP-9 expression levels were significantly downregulated in MG-63 and U2-OS cells $(\mathrm{P}<0.05)$, which was consistent with the aforementioned conclusions, and confirmed that $\mathrm{CK}$ inhibited the migration and invasion of osteosarcoma cells.

$C K$ is involved in the PI3K/mTOR/p70S6K1 signaling pathway in osteosarcoma cells. To further investigate the antitumor mechanism of CK on MG-63 and U2-OS cells, the expression levels of related proteins in the $\mathrm{PI} 3 \mathrm{~K} / \mathrm{mTOR} / \mathrm{p} 70 \mathrm{~S} 6 \mathrm{~K} 1$ signaling pathway were investigated. The results of western blot analyses revealed that after treatment with $\mathrm{CK}, \mathrm{PTEN}$ the major blocking protein of the $\mathrm{PI} 3 \mathrm{~K} / \mathrm{mTOR} / \mathrm{p} 70 \mathrm{~S} 6 \mathrm{~K} 1$ pathway was significantly upregulated in MG-63 and U2-OS cells $(\mathrm{P}<0.05$; Fig. 7A). However, the core action proteins of the PI3K/mTOR/p70S6K1 pathway, including $\mathrm{p}-\mathrm{AKT}$ and $\mathrm{p}-\mathrm{mTOR}$, were significantly downregulated in the $\mathrm{CK}$ group $(\mathrm{P}<0.05$; Fig. $7 \mathrm{~A}$ and $\mathrm{B})$, indicating that the $\mathrm{PI} 3 \mathrm{~K} / \mathrm{mTOR} / \mathrm{p} 70 \mathrm{~S} 6 \mathrm{~K} 1$ pathway was blocked 
A

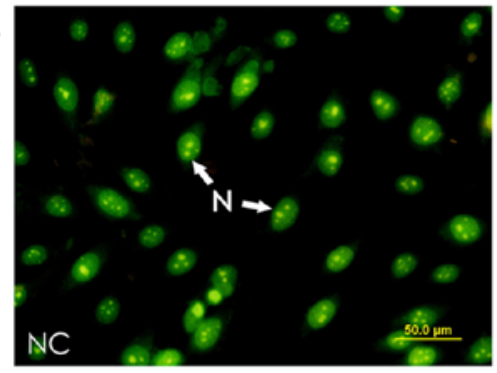

B

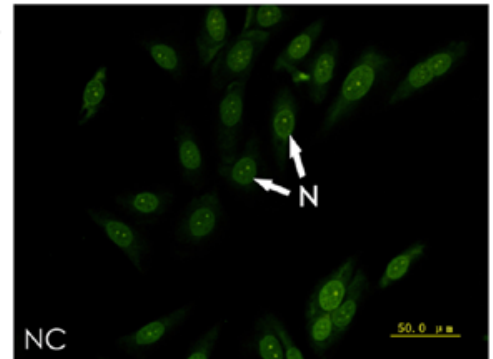

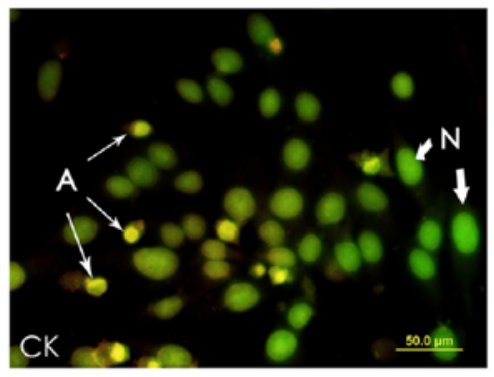
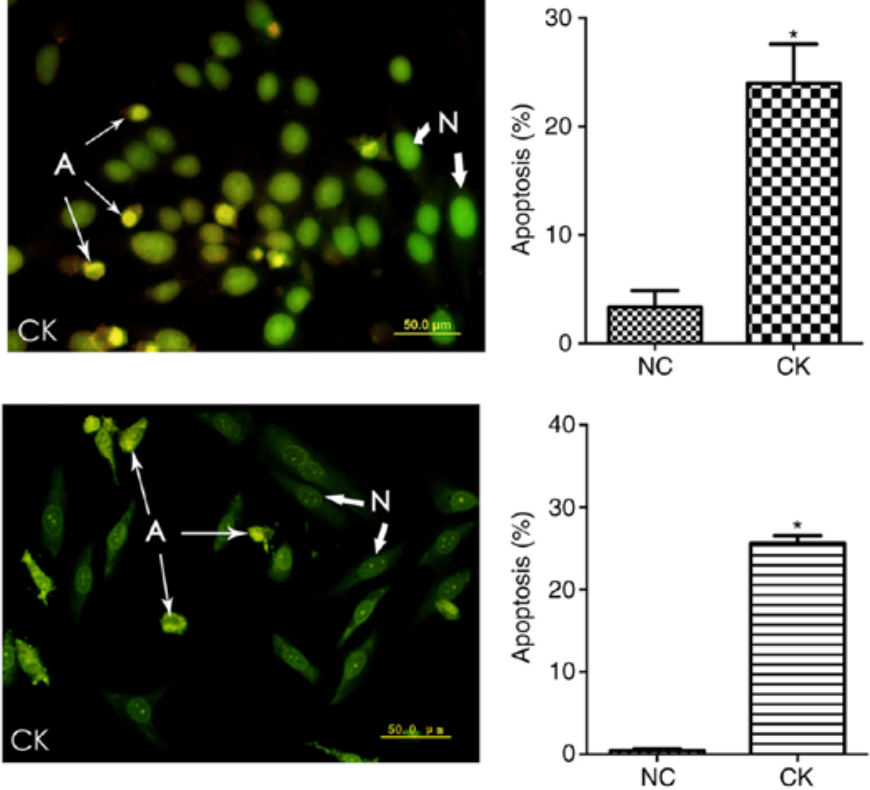

Figure 3. Apoptosis-related morphological changes of cell nuclei induced by CK in MG63 and U2-OS cells. (A and B) Cells were treated with or without CK $(20 \mu \mathrm{M})$ and cell nuclei were stained with $\mathrm{AO} / \mathrm{EB}$ and observed under a fluorescence microscope. Cells with condensed or fragmented nuclei were considered apoptotic, and early apoptotic nuclei presented as green or light yellow; late apoptotic nuclei presented as orange or red (N, normal nuclei; A, apoptotic nuclei). Experiments were repeated three times. ${ }^{*} \mathrm{P}<0.05$ vs. the $\mathrm{NC}$ group. $\mathrm{CK}$, ginsenoside compound $\mathrm{K}$; $\mathrm{AO} / \mathrm{EB}$, acridine orange/ethidium bromide; $\mathrm{NC}$, normal control.

A
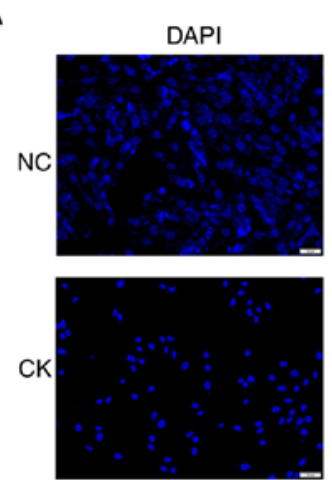

B
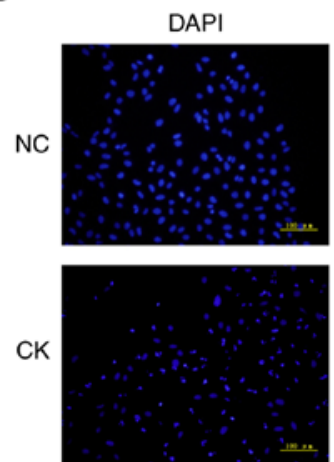
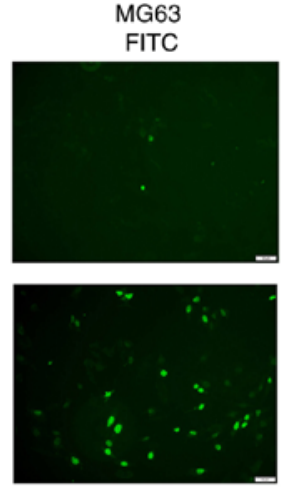

U2-OS

FITC
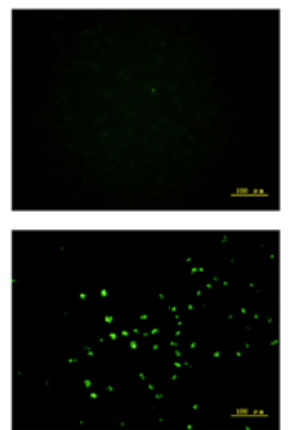

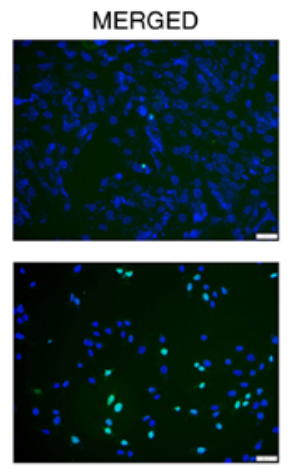

MERGED
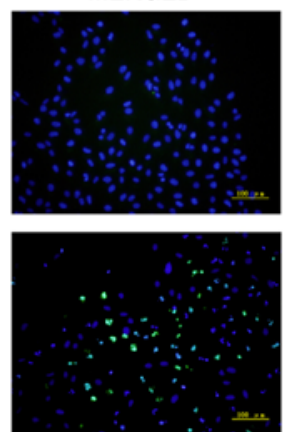
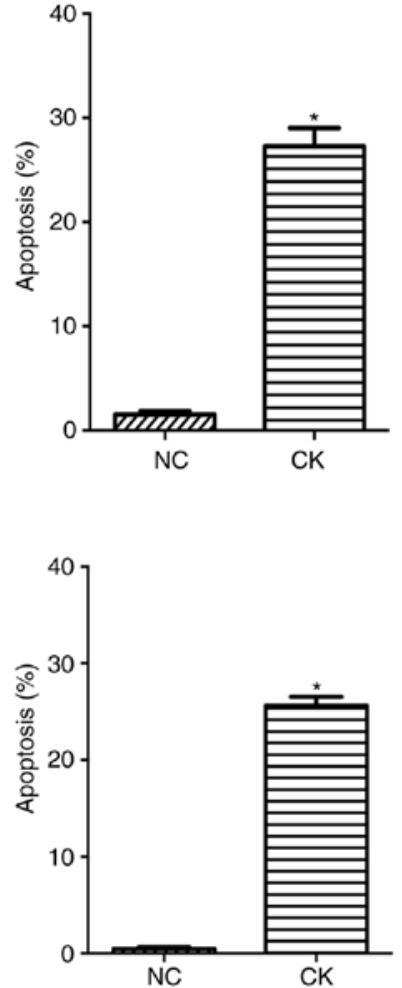

Figure 4. Apoptotic changes of cell nuclei induced by CK in MG63 and U2-OS cells detected by TUNEL assays. (A and B) Cells were treated with or without CK $(20 \mu \mathrm{M})$ and cell nuclei were stained with DAPI and TUNEL assay solution and observed under a fluorescence microscope. Normal nuclei exhibited regular elliptical shapes and were stained blue by DAPI; apoptotic nuclei presented as condensed or fragmented and were stained green by TUNEL assay solution. Compared with the control group, the CK group exhibited significant apoptosis. Data are expressed as the means \pm SEM. All experiments were repeated three times. " $\mathrm{P}<0.05$ vs. the $\mathrm{NC}$ group. $\mathrm{CK}$, ginsenoside compound $\mathrm{K}$; $\mathrm{NC}$, normal control.

after treatment with $\mathrm{CK}$. The downregulation of p70S6K1 expression in the $\mathrm{CK}$ group $(\mathrm{P}<0.05$; Fig. $7 \mathrm{~B})$ further confirmed this conclusion. Furthermore, the expression levels of p-mTOR and p70S6K1 were downregulated when treated with RAD001 
A

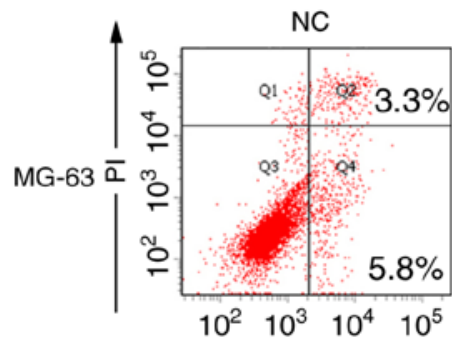

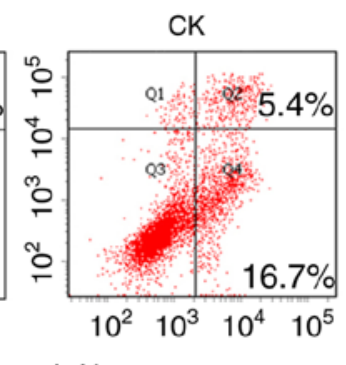
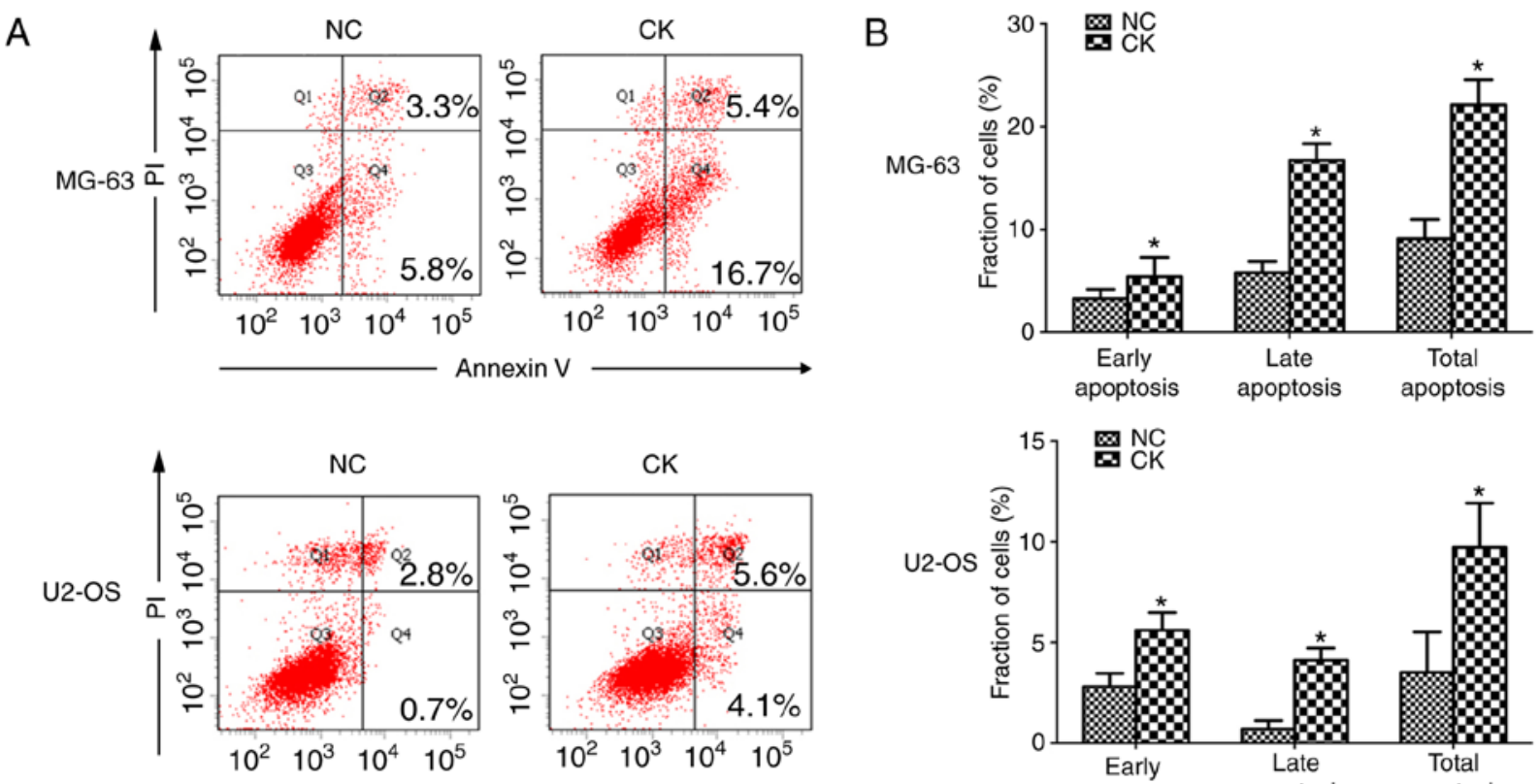

C

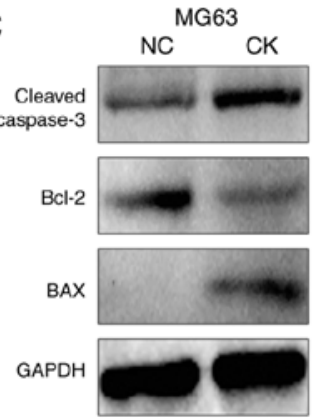

- Annexin V
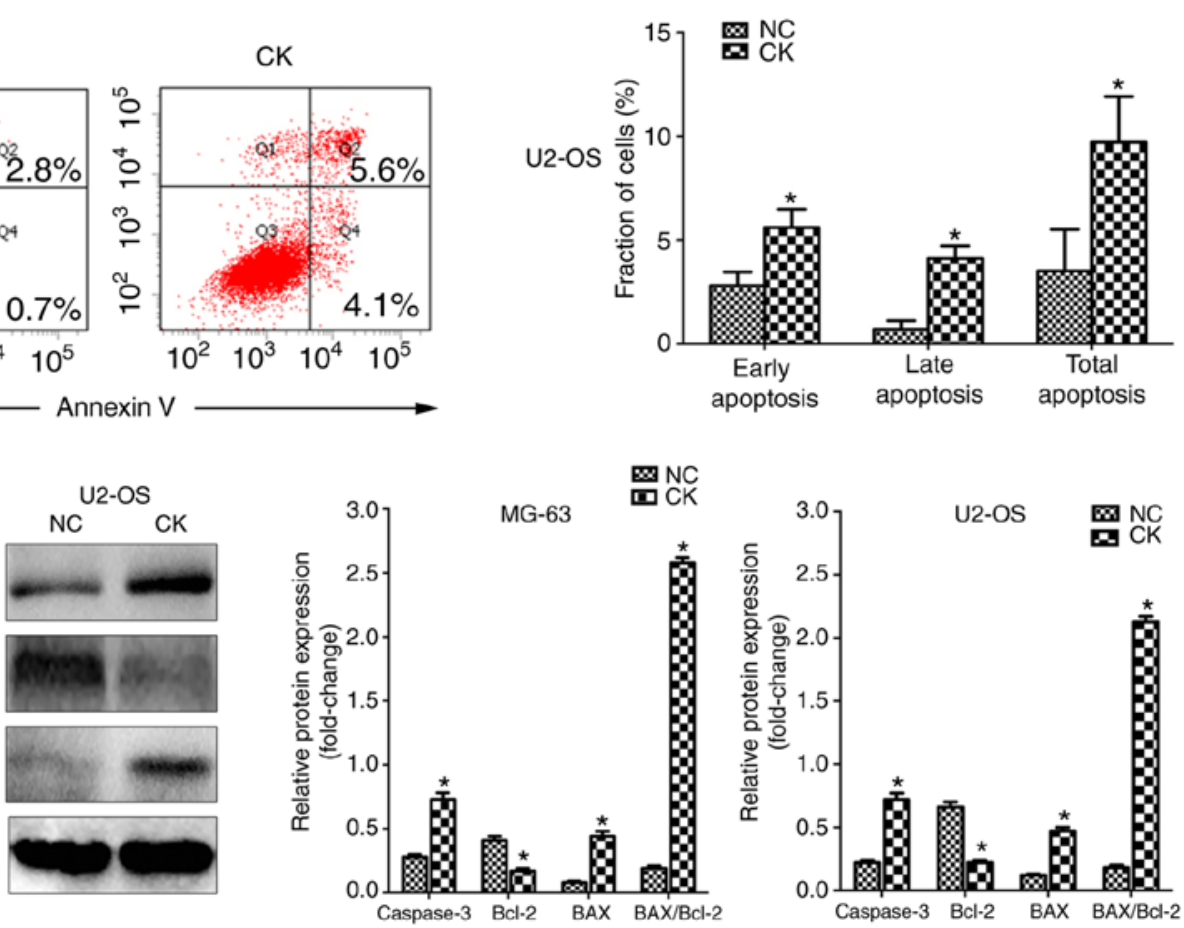

Figure 5. Determination of apoptosis in MG63 and U2-OS cells via Annexin V/PI staining and western blot analyses. (A) Annexin V/PI apoptosis detection kits were used to detect the induction of apoptosis. Early apoptosis is localized in the bottom right area and late apoptosis in the top right area. (B) Whether early or late apoptosis, the apoptotic ratio in the CK groups was significantly higher than that in the control group. "P<0.05 vs. the NC group. (C) Detection of the expression of apoptosis-related proteins (cleaved caspase-3, Bcl-2, and BAX) by western blot analyses. Cleaved caspase-3 and BAX expression levels were upregulated, while Bcl-2 expression was downregulated, in both MG63 and U2-OS cells after treatment with CK. In addition, the ratio of BAX/Bcl-2 was upregulated in both groups. " $\mathrm{P}<0.05$ vs. the NC. All data represent the mean $\pm \mathrm{SEM}$ of three independent experiments. CK, ginsenoside compound K; $\mathrm{NC}$, normal control.

in U2-OS cells, which was consistent with the effect of CK. When cells were treated with both CK and RAD001, they played a synergistic role and the downregulation of the expression levels of p-mTOR and p70S6K1 were more pronounced (Fig. 7C). Overall, these conclusions confirmed that CK blocked the $\mathrm{PI} 3 \mathrm{~K} / \mathrm{mTOR} / \mathrm{p} 70 \mathrm{~S} 6 \mathrm{~K} 1$ signaling pathway of MG-63 and U2-OS osteosarcoma cells.

\section{Discussion}

Ginsenoside CK is one of the main metabolites of ginsenoside, which is a glycoside compound composed of sugars and aglycones, and belongs to a triterpenoid compound family. According to the structure of sapogenin, it can be divided into three categories: One is an oleanane-type pentacyclic triterpenoid saponin, the sapogenin is oleanolic acid, and the other two are dammarane-type tetracyclic triterpenoid saponins, which are the majority of ginsenosides and are the primary active ingredients of ginseng. According to different aglycons, the dammarane type tetracyclic triterpenoid saponin can be divided into the original ginseng diol saponin and the original ginseng triol saponin. Ginsenoside CK, a major member of the originally reported ginseng diol saponin, has been a topic of research in the fields of anti-inflammatory and antitumor effects. Recent studies have revealed that ginsenoside CK has anti-inflammatory, antioxidative, and neuroprotective effects (13-16), and of particular interest are its antitumor effects.

Studies have confirmed that CK has an inhibitory effect on various tumor cells, including liver, lung, breast and colon cancer as well as leukemia (12,17-19). The antitumor effect of CK is mainly reflected in its ability to significantly attenuate the proliferation, invasion, and migration of tumor cells. Lee et al (20) revealed that CK significantly inhibited the proliferation and invasion of malignant glioma cells by blocking the $\mathrm{PI} 3 \mathrm{~K} / \mathrm{AKT} / \mathrm{mTOR}$ signaling pathway. Kang et al (21) reported that $\mathrm{CK}$ inhibited colon cancer cell proliferation and induced apoptosis by inhibiting histone deacetylase activity. 

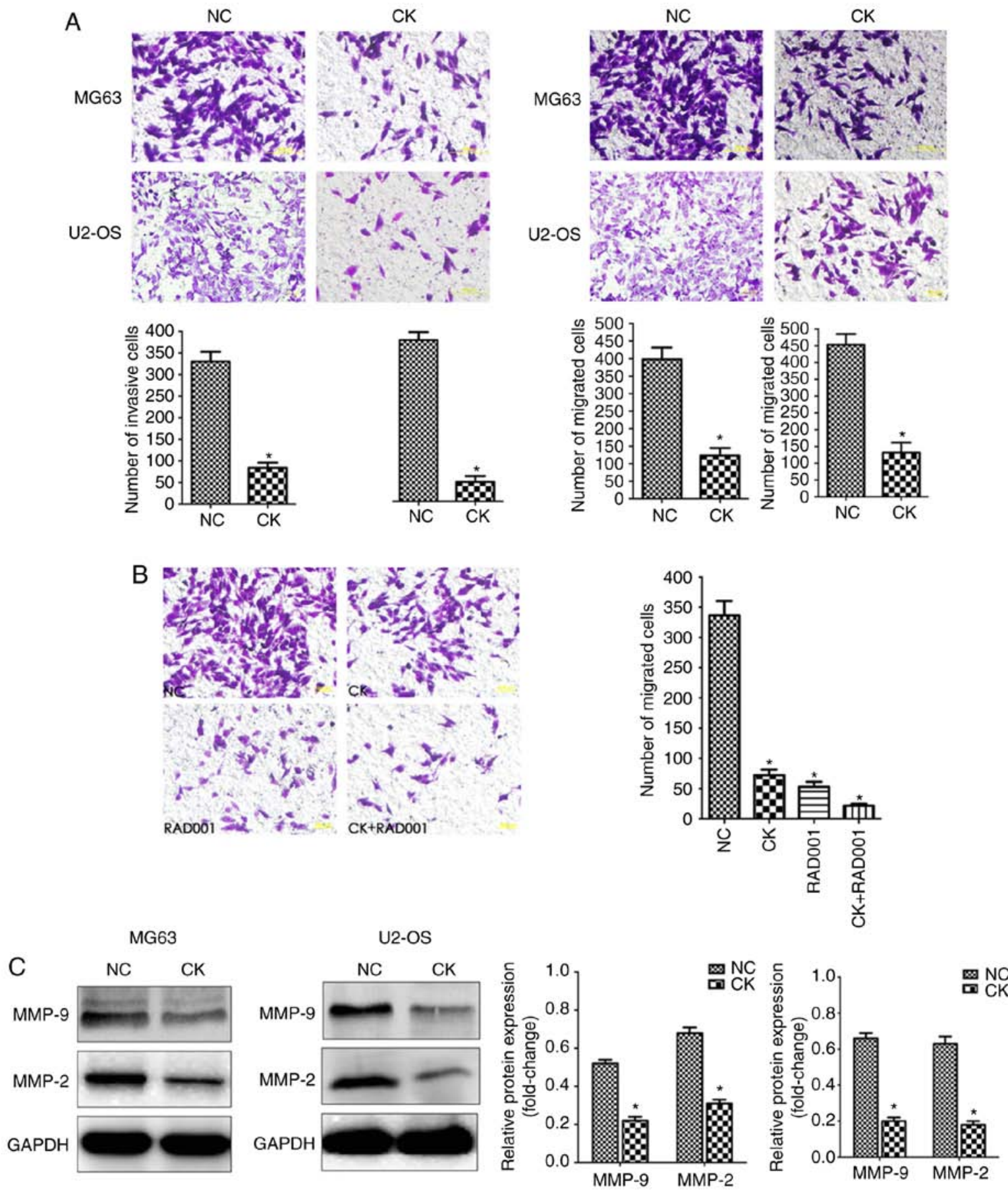

Figure 6. Migration and invasion of MG63 and U2-OS cells after treatment with CK. (A) Cell invasion and migration abilities were detected by Transwell migration assays and observed under an inverted phase-contrast microscope. Histogram analyses revealed that CK effectively inhibited both the migration and invasion of MG63 and U2-OS cells. " P<0.05 vs. the NC group. (B) RAD001, a specific inhibitor of mTOR, was added. The number of U2-OS cells in the CK or RAD001 group passing through the Transwell chamber membrane was significantly lower than in the NC group, and this trend was more pronounced when cells were treated with both $\mathrm{CK}$ and RAD001. "P<0.05 vs. the NC group. (C) Western blots revealed that CK downregulated the expression of invasion-related proteins (MMP-2 and MMP-9) in both MG63 and U2-OS cells. ${ }^{*} \mathrm{P}<0.05$ vs. the NC group. CK, ginsenoside compound K; NC, normal control.

Osteosarcoma is one of the most malignant bone tumors, and its lethality is mainly reflected in the malignant, diffuse proliferative capacity, and early tumor metastasis. Therefore, it was speculated whether CK also had an inhibitory effect on the proliferation and invasion of osteosarcoma cells. To demonstrate the effect of $\mathrm{CK}$ on the in vitro viability and proliferation of osteosarcoma cells in this study, MG-63 and U2-OS cells were treated with CK. Both MTT and BrdU assay results confirmed that $\mathrm{CK}$ significantly reduced the viability and proliferation of MG-63 and U2-OS cells in vitro. Furthermore, it was revealed that the effect of CK on cell proliferation may be related to cell cycle distribution. Using PI staining cell cycle analyses in both MG-63 and U2-OS cells, it was determined that $\mathrm{CK}$ altered the distribution of cell cycle stages. After treatment with CK, the S-phase ratio of MG-63 cells decreased from $51.06 \pm 3.31$ to $36.96 \pm 3.07 \%$, compared to the control group, while the G2/M-phase ratio increased from $16.39 \pm 2.59$ to $35.23 \pm 2.33 \%$. Similarly, the proportion 
A

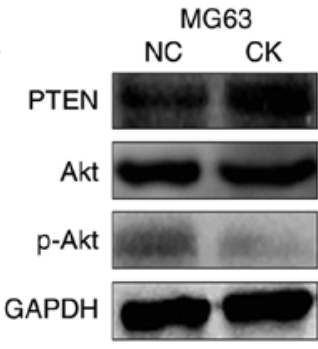

B

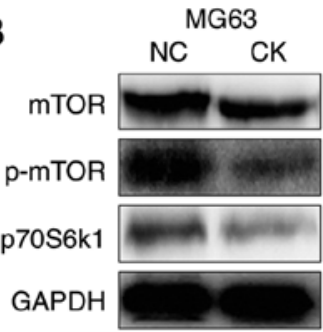

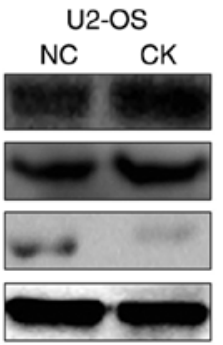

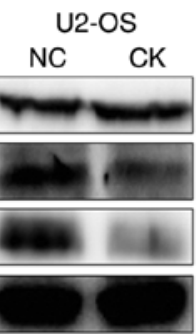

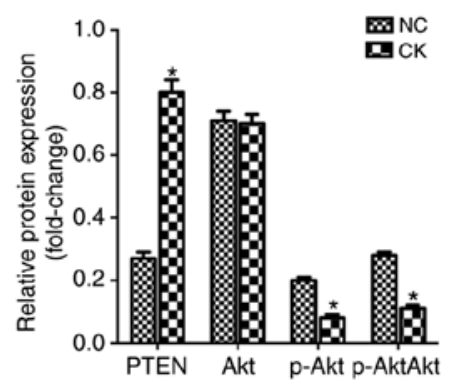
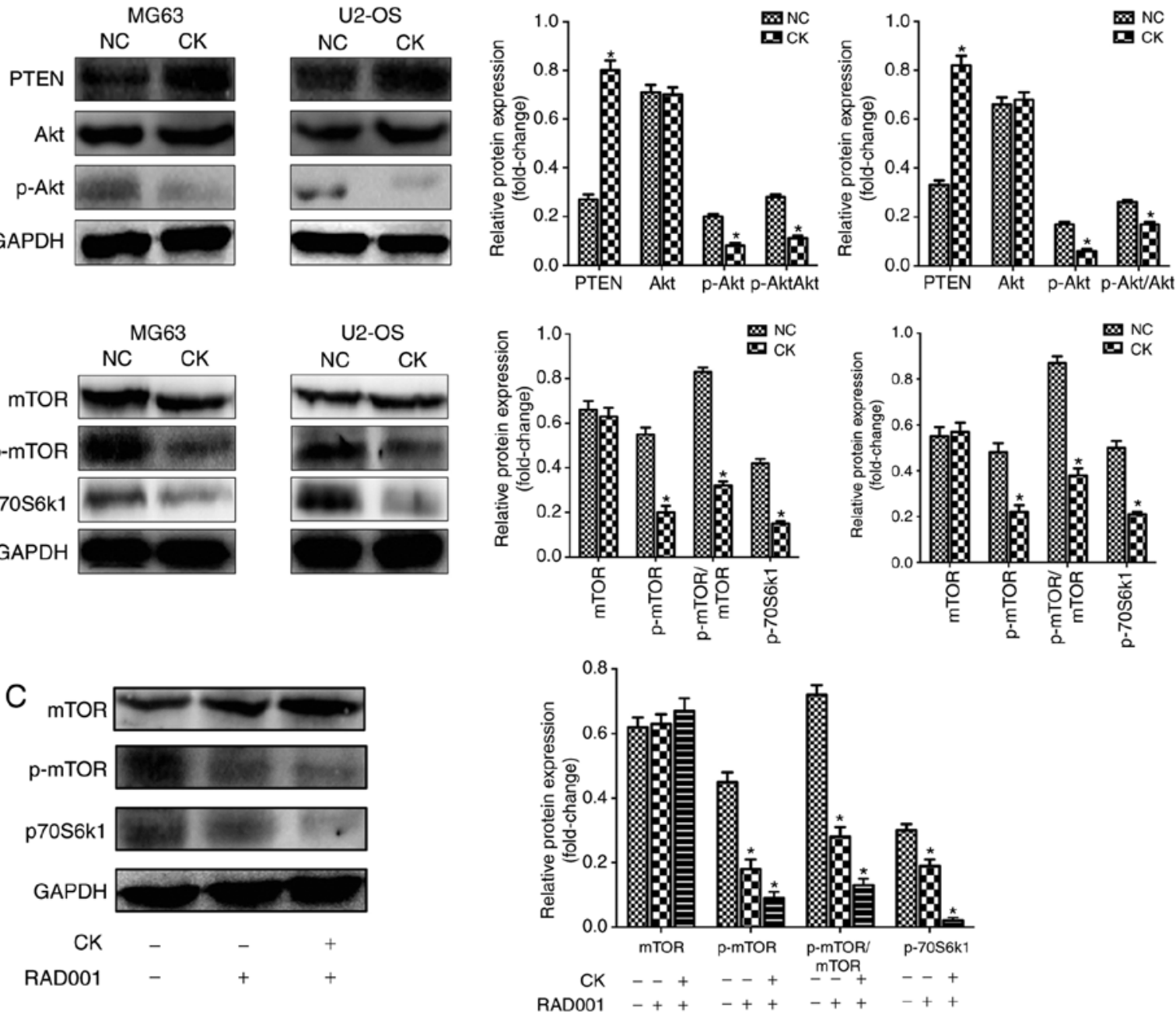

Figure 7. Western blot analyses of proteins in the PI3K/mTOR/p70S6K1 signaling pathway of MG63 and U2-OS cells. (A) PTEN expression was upregulated while p-Akt expression and the ratio of p-Akt/Akt were downregulated in both MG63 and U2-OS cells after treatment with CK ("P<0.05 vs. the NC group). (B) p-mTOR, the ratio of p-mTOR/mTOR and p-70S6k1 expression levels were downregulated in both MG63 and U2-OS cells after treatment with CK ( $\mathrm{P}<0.05$ vs. the NC group). (C) The expression levels of p-mTOR, the ratio of p-mTOR/mTOR and p70S6K1 were downregulated when treated with RAD001 in U2-OS cells, and the downregulation was more pronounced when treated with both CK and RAD001. "P<0.05 vs. the NC group. All data represent the mean \pm SEM of three independent experiments. CK, ginsenoside compound $\mathrm{K}$; NC, normal control.

of the S phase decreased from $38.00 \pm 3.57$ to $28.73 \pm 4.08 \%$, while the proportion of the $\mathrm{G} 2 / \mathrm{M}$ phase increased from $36.25 \pm 2.77$ to $45.96 \pm 3.41 \%$ in U2-OS cells. Therefore, it was demonstrated that CK induced G2/M-phase cell cycle arrest, and inhibited the viability and proliferation of MG-63 and U2-OS cells.

In order to analyze the apoptosis-inducing effect of $\mathrm{CK}$, apoptotic cell nuclear morphology assays, Annexin V/PI staining assays, and western blot analyses were performed. It was determined that the cell nuclei of the CK-treated group exhibited typical apoptotic morphological changes. Similar results were detected by TUNEL assays, whether using MG-63 or U2-OS cells. The apoptotic nuclei were stained green, while the normal nuclei without apoptosis were stained blue by DAPI staining. The aforementioned results demonstrated that $\mathrm{CK}$ had an apoptosis-inducing effect on both MG-63 and U2-OS cells using nuclear apoptotic morphological assays.

Therefore, using nuclear apoptotic morphological assays, it was confirmed that $\mathrm{CK}$ had a significant apoptosis-inducing effect on osteosarcoma cells, and the conclusions were further confirmed by Annexin V/PI staining and western blot analyses. In both MG-63 and U2-OS cells, early apoptosis $(5.42 \pm 1.90$ and $5.66 \pm 0.88 \%)$ and late apoptosis $(16.71 \pm 1.65$ and $4.17 \pm 0.60 \%)$ were significantly higher in the CK-treated group than in the control group. The expression levels of cleaved caspase- 3 and BAX, key proteins in the apoptotic pathway, were significantly upregulated in the CK group, and the downregulation of the anti-apoptotic protein, Bcl-2, further confirmed the activation of apoptosis. These results confirmed that CK-induced apoptosis in MG-63 and U2-OS cells at the level of cellular signaling pathways.

The aforementioned results revealed that $\mathrm{CK}$ inhibited proliferation and induced apoptosis of MG-63 and U2-OS cells, and the results are consistent with previous studies which revealed that $\mathrm{CK}$ has antitumor effects on various tumor cells, including liver, lung, breast and colon cancer as well as leukemia (17-21); however, another characteristic feature of osteosarcoma cells is their aggressive invasiveness and early metastasis. Since osteosarcoma is prone to early metastasis (most common in lung), most patients lose the opportunity for surgical treatment, and there is no effective 
radiotherapy and chemotherapy for osteosarcoma in the clinic. Thus, patients usually have a poor prognosis and a high mortality rate $(22,23)$.

To investigate the effects of $\mathrm{CK}$ on the migration and invasion of MG-63 and U2-OS cells, a Transwell assay was used and the expression levels of the invasion-related proteins, MMP-2 and MMP-9, were detected. The migration and invasion of MG-63 and U2-OS cells significantly decreased after treatment with $\mathrm{CK}$, and downregulation of the expression of MMP-2 and MMP-9 also demonstrated that CK inhibited the migration and invasion of MG-63 and U2-OS cells. CK played a similar role to RAD001, a specific inhibitor of mTOR, and together they played a synergistic role in the effects of the migration and invasion. Chawla et al (24) reported that the mTOR inhibitor, Ridaforolimus, inhibited the phosphorylation of the mTOR effector protein, S6K, to block the PI3K/AKT pathway. Such inhibition also effectively inhibited the tumor characteristics of osteosarcoma, and achieved significant clinical effects. Moriceau et al (25) reported that the mTOR inhibitor, RAD001 (Everolimus), inhibited osteosarcoma cell proliferation in a dose- and time-dependent manner. Manara et al (26) reported that NVP-BEZ235, another mTOR inhibitor, significantly inhibited the proliferation and invasion of osteosarcoma cells, and was a possible novel potential targeted drug for the treatment of osteosarcoma. A number of previous studies have demonstrated that blocking the $\mathrm{PI} 3 \mathrm{~K} / \mathrm{mTOR} / \mathrm{p} 70 \mathrm{~S} 6 \mathrm{~K} 1$ signaling pathway by mTOR inhibitors inhibited osteosarcoma cell activity. Therefore, it was speculated that osteosarcoma cells may play a pathogenic role through the PI3K/mTOR/p70S6K1 pathway.

$\mathrm{PI} 3 \mathrm{~K} / \mathrm{mTOR} / \mathrm{p} 70 \mathrm{~S} 6 \mathrm{~K} 1$ studies have been a popular research topic in recent years. As an essential signaling pathway in cells, it plays an important biological function in cell growth, proliferation, apoptosis, angiogenesis, and autophagy. Disorders of the pathway can cause a range of diseases, including cancer, neuropathy, and autoimmune diseases (27). The phosphatidylinositol 3-kinase (PI3K) protein family is involved in the regulation of various cellular functions such as cell proliferation, differentiation, apoptosis, and glucose transport. Increases in PI3K activity are often associated with a variety of cancers (28). Cytokines such as fibroblast growth factor (FGF), vascular endothelial growth factor (VEGF), human growth factor (HGF), vascular protein I (Ang1), and insulin activate PI3Ks, and the $\mathrm{SH} 2$ and $\mathrm{SH} 3$ domains of the p85 subunit of PI3Ks bind to the adaptor protein at a phosphorylation site. PI3K initiates phosphorylation of various PI intermediates after recruitment of activated receptors. Following this, PI3K converts PIP2 into PIP3, a process that is particularly relevant to tumors (29). The result of PI3K activation is the generation of a second messenger, PIP3, on the plasma membrane. PIP3 binds to the PH domain-containing signaling proteins, AKT and phosphoinositide dependent kinase-1 (PDK1), which promotes PDK1 phosphorylation of AKT Ser308 to activate AKT (30,31). Phosphorylated AKT activates the mTOR complex (mTORC1), which activates the translation of proteins and enhances cell growth. AKT exerts anti-apoptotic effects by phosphorylating target proteins through various downstream pathways. ATK activates $\mathrm{I} \kappa \mathrm{B}$ kinase (IKK $\alpha$ ), which leads to the degradation of the NF- $\mathrm{KB}$

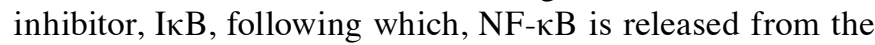

cytoplasm for nuclear translocation, and its target gene is activated to promote cell survival. AKT phosphorylates the Bcl-2 family member, $\mathrm{BAD}$, which binds to 14-3-3 and prevents it from binding to Bcl-XL to initiate apoptosis $(32,33)$.

PTEN is a PIP3-phosphatase that, in contrast to PI3K, converts PIP3 to PI-4,5-P2 by dephosphorylation. PTEN reduces AKT activation and blocks all downstream signaling events regulated by AKT (34). Previous studies have confirmed that PTEN expression in osteosarcoma cells is significantly decreased compared to normal tissues $(7,35)$, indicating that the pathogenicity of osteosarcoma is related to PTEN expression. In the present study, the expression of PTEN in MG-63 and U2-OS cells was significantly upregulated in CK-treated cells $(\mathrm{P}<0.05)$. In contrast, the expression levels of p-Akt and p-mTOR were downregulated compared with the control group $(\mathrm{P}<0.05)$. However, the expression of Akt and mTOR was not significantly altered in the two groups $(\mathrm{P}>0.05)$, indicating blockage of the PI3K/AKT pathway, as described previously. The phosphorylation of Akt was inhibited and the downstream mTOR complex could not be activated normally; thus, inhibiting cell viability and proliferation. Concurrently, the apoptotic proteins, caspase-3 and BAX were activated, which blocked apoptosis inhibition and triggered apoptosis.

p70S6K1 is a direct substrate downstream of p-mTOR. Phosphorylation of p70s6k1 by p-mTOR promotes the formation of ribosomes, initiation factors, and elongation factors in cells, and promotes the invasion and metastasis of tumor cells (8). The expression of p70s6k1 in MG-63 and U2-OS cells was significantly downregulated after CK treatment $(\mathrm{P}<0.05)$, indicating that the $\mathrm{PI} 3 \mathrm{~K} / \mathrm{mTOR} / \mathrm{p} 70 \mathrm{~S} 6 \mathrm{~K} 1$ signaling pathway was blocked, and the invasion and metastasis of tumor cells was inhibited. When RAD001 was added, the $\mathrm{PI} 3 \mathrm{~K} / \mathrm{mTOR} / \mathrm{p} 70 \mathrm{~S} 6 \mathrm{~K} 1$ signaling pathway was blocked, the expression levels of p-mTOR and p70S6K1 were downregulated, and this result was consistent with the effect of CK. Furthermore, CK and RAD001 played a synergistic role in regulating the expression of proteins in the PI3K/mTOR/p70S6K1 signaling pathway.

In summary, the present study revealed that CK inhibited the viability and proliferation of osteosarcoma cells, which was related to G2/M-phase cell cycle arrest. CK induced apoptosis and inhibited the migration and invasion of osteosarcoma cells, and blocked the PI3K/mTOR/p70S6K1 signaling pathway of MG-63 and U2-OS osteosarcoma cells, which exhibited anti-tumor properties in osteosarcoma cells. However, this study also has some limitations. Cell viability assays on normal osteocyte cells as a healthy control group should be performed. Research on PARP activation status and the EGFR/RAS/MAPK pathways needs to be performed, to demonstrate the pro-oxidant or antioxidant effects of Ginsenoside CK in MG63 and U2-OS cells to further confirm our conclusion. In addition, apoptosis-related proteins, such as cleaved caspase-9 and cleavage of PARP-1 should also be investigated to research the specific mechanism of mitochondrial apoptosis induced by CK. The MAPK pathway is an important signaling pathway regulating osteosarcoma cells, and its relationship with $\mathrm{CK}$ and the $\mathrm{PI} 3 \mathrm{~K} / \mathrm{mTOR} / \mathrm{p} 70 \mathrm{~S} 6 \mathrm{~K} 1$ signaling pathway still requires further study. 


\section{Acknowledgements}

Not applicable.

\section{Funding}

Not applicable.

\section{Availability of data and materials}

The analyzed data sets generated during the study are available from the corresponding author on reasonable request.

\section{Authors' contributions}

$\mathrm{KC}$ and QR conceived and designed all the experiments. YW, $\mathrm{ZM}, \mathrm{ZL}$, and BS participated in the cell experiments. JJ, JX, TC and YH analyzed the results. YJ and LQ participated in the writing of the manuscript and revising it critically for important intellectual content. All the authors reviewed and approved the final manuscript and agree to be accountable for all aspects of the research in ensuring that the accuracy or integrity of any part of the work are appropriately investigated and resolved.

\section{Ethics approval and consent to participate}

Not applicable.

\section{Patient consent for publication}

Not applicable.

\section{Competing interests}

The authors declare that they have no competing interests.

\section{References}

1. Nagao-Kitamoto H, Setoguchi T, Kitamoto S, Nakamura S, Tsuru A, Nagata M, Nagano S, Ishidou Y, Yokouchi M, Kitajima S, et al: Ribosomal protein S3 regulates GLI2-mediated osteosarcoma invasion. Cancer Lett 356: 855-861, 2015.

2. Sevelda F, Mayr L, Kubista B, Lötsch D, van Schoonhoven S, Windhager R, Pirker C, Micksche M and Berger W: EGFR is not a major driver for osteosarcoma cell growth in vitro but contributes to starvation and chemotherapy resistance. J Exp Clin Cancer Res 34: 134, 2015.

3. Lewis VO: What's new in musculoskeletal oncology. J Bone Joint Surg Am 91: 1546-1556, 2009.

4. Judson I, Verweij J, Gelderblom H, Hartmann JT, Schöffski P, Blay JY, Kerst JM, Sufliarsky J, Whelan J and Hohenberger P: Doxorubicin alone versus intensified doxorubicin plus ifosfamide for first-line treatment of advanced or metastatic soft-tissue sarcoma: A randomised controlled phase 3 trial. Lancet Oncol 15 : 415-423, 2014.

5. Miller BJ, Gao Y and Duchman KR: Socioeconomic measures influence survival in osteosarcoma: An analysis of the national cancer data base. Cancer Epidemiol 49: 112-117, 2017.

6. Zhang Y, Kwok-Shing Ng P, Kucherlapati M, Chen F, Liu Y, Tsang YH, de Velasco G, Jeong KJ, Akbani R, Hadjipanayis A, et al: A pan-cancer proteogenomic atlas of $\mathrm{PI} 3 \mathrm{~K} / \mathrm{AKT} / \mathrm{mTOR}$ pathway alterations. Cancer Cell 31: 820-832, 2017.

7. Dowling RJ, Topisirovic I, Fonseca BD and Sonenberg N: Dissecting the role of mTOR: Lessons from mTOR inhibitors. Biochim Biophy Acta 1804: 433-439, 2010.
8. Fan QW and Weiss WA: Inhibition of PI3K-Akt-mTOR signaling in glioblastoma by mTORC1/2 inhibitors. Methods Mol Biol 821: 349-359, 2012.

9. Hossen MJ, Hong YD, Baek KS, Yoo S, Hong YH, Kim JH Lee JO, Kim D, Park J and Cho JY: In vitro antioxidative and anti-inflammatory effects of the compound k-rich fraction BIOGF1K, prepared from panax ginseng. J Ginseng Res 41: 43-51, 2017.

10. Chen L, Meng Y, Sun Q, Zhang Z, Guo X, Sheng X, Tai G, Cheng $\mathrm{H}$ and Zhou Y: Ginsenoside compound $\mathrm{K}$ sensitizes human colon cancer cells to TRAIL-induced apoptosis via autophagy-dependent and -independent DR5 upregulation. Cell Death Dis 7: e2334, 2016.

11. Li W, Zhang M, Gu J, Meng ZJ, Zhao LC, Zheng YN, Chen L and Yang GL: Hypoglycemic effect of protopanaxadiol-type ginsenosides and compound $\mathrm{k}$ on type 2 diabetes mice induced by high-fat diet combining with streptozotocin via suppression of hepatic gluconeogenesis. Fitoterapia 83: 192-198, 2012.

12. Wei S, Li W, Yu Y, Yao F, A L, Lan X, Guan F, Zhang M and Chen L: Ginsenoside compound K suppresses the hepatic gluconeogenesis via activating adenosine-5'monophosphate kinase: A study in vitro and in vivo. Life Sci 139: 8-15, 2015.

13. Ahuja A, Kim JH, Kim JH, Yi YS and Cho JY: Functional role of ginseng-derived compounds in cancer. J Ginseng Res 42: 248-254, 2018.

14. Muthukumar T, Aravinthan A, Sharmila J, Kim NS and Kim JH: Collagen/chitosan porous bone tissue engineering composite scaffold incorporated with ginseng compound K. Carbohydr Polym 152: 566-574, 2016.

15. Yang L, Zhang Z, Hou J, Jin X, Ke Z, Liu D, Du M, Jia X and $\mathrm{Lv} \mathrm{H}$ : Targeted delivery of ginsenoside compound $\mathrm{K}$ using TPGS/PEG-PCL mixed micelles for effective treatment of lung cancer. Int J Nanomedicine 12: 7653-7667, 2017.

16. Yang XD, Yang YY, Ouyang DS and Yang GP: A review of biotransformation and pharmacology of ginsenoside compound K. Fitoterapia 100: 208-220, 2015.

17. Li Y, Zhou T, Ma C, Song W, Zhang J and Yu Z: Ginsenoside metabolite compound $\mathrm{K}$ enhances the efficacy of cisplatin in lung cancer cells. J Thorac Dis 7: 400-406, 2015.

18. Yang L, Xin J, Zhang Z, Yan H, Wang J, Sun E, Hou J, Jia X and $\mathrm{Lv} \mathrm{H}$ : TPGS-modified liposomes for the delivery of ginsenoside compound $\mathrm{K}$ against non-small cell lung cancer: Formulation design and its evaluation in vitro and in vivo. J Pharm Pharmacol 68: 1109-1118, 2016.

19. Zhang K and Li Y: Effects of ginsenoside compound $k$ combined with cisplatin on the proliferation, apoptosis and epithelial mesenchymal transition in MCF-7 cells of human breast cancer. Pharm Biol 54: 561-568, 2016.

20. Lee S, Kwon MC, Jang JP, Sohng JK and Jung HJ: The ginsenoside metabolite compound $\mathrm{K}$ inhibits growth, migration and stemness of glioblastoma cells. Int J Oncol 51: 414-424, 2017.

21. Kang KA, Piao MJ, Kim KC, Zheng J, Yao CW, Cha JW, Kim HS, Kim DH, Bae SC and Hyun JW: Compound k, a metabolite of ginseng saponin, inhibits colorectal cancer cell growth and induces apoptosis through inhibition of histone deacetylase activity. Int J Oncol 43: 1907-1914, 2013.

22. Ren T, Zheng B, Huang Y, Wang S, Bao X, Liu K and Guo W: Osteosarcoma cell intrinsic PD-L2 signals promote inv asion and metastasis via the RhoA-ROCK-LIMK2 and autophagy pathways. Cell Death Dis 10: 261, 2019.

23. Yu X, Hu L, Li S, Shen J, Wang D, Xu R and Yang H: Long non-coding RNA taurine upregulated gene 1 promotes osteosarcoma cell metastasis by mediating HIF-1 $\alpha$ via miR-143-5p. Cell Death Dis 10: 280, 2019.

24. Chawla SP, Staddon AP, Baker LH, Schuetze SM, Tolcher AW, D'Amato GZ, Blay JY, Mita MM, Sankhala KK, Berk L, et al: Phase II study of the mammalian target of rapamycin inhibitor ridaforolimus in patients with advanced bone and soft tissue sarcomas. J Clin Oncol 30: 78-84, 2012

25. Moriceau G, Ory B, Mitrofan L, Riganti C, Blanchard F, Brion R, Charrier C, Battaglia S, Pilet P, Denis MG, et al: Zoledronic acid potentiates mTOR inhibition and abolishes the resistance of osteosarcoma cells to RAD001 (Everolimus): Pivotal role of the prenylation process. Cancer Res 70: 10329-10339, 2010.

26. Manara MC, Nicoletti G, Zambelli D, Ventura S, Guerzoni C, Landuzzi L, Lollini PL, Maira SM, García-Echeverría C, Mercuri M, et al: NVP-BEZ235 as a new therapeutic option for sarcomas. Clin Cancer Res 16: 530-540, 2010. 
27. Engelman JA, Luo J and Cantley LC: The evolution of phosphatidylinositol 3-kinases as regulators of growth and metabolism. Nat Rev Genet 7: 606-619, 2006.

28. Fruman DA and Rommel C: PI3K and cancer: Lessons, challenges and opportunities. Nat Rev Drug Discov 13: 140-156, 2014.

29. Gewinner C, Wang ZC, Richardson A, Teruya-Feldstein J, Etemadmoghadam D, Bowtell D, Barretina J, Lin WM, Rameh L, Salmena L, et al: Evidence that inositol polyphosphate 4-phosphatase type II is a tumor suppressor that inhibits PI3K signaling. Cancer Cell 16: 115-125, 2009.

30. Hay N: Interplay between FOXO, TOR, and AKT. Biochim Biophys Acta 1813: 1965-1970, 2011.

31. Laplante M and Sabatini DM: MTOR signaling in growth control and disease. Cell 149: 274-293, 2012.

32. Mabuchi S, Hisamatsu T and Kimura T: Targeting mTOR signaling pathway in ovarian cancer. Curr Med Chem 18: 2960-2968, 2011.
33. Wu SH, Bi JF, Cloughesy T, Cavenee WK and Mischel PS: Emerging function of mTORC2 as a core regulator in glioblastoma: Metabolic reprogramming and drug resistance. Cancer Biol Med 11: 255-263, 2014.

34. Yuan H and Gao Y: MicroRNA-1908 is upregulated in human osteosarcoma and regulates cell proliferation and migration by repressing PTEN expression. Oncol Rep 34: 2706-2714, 2015.

35. Kawano M, Tanaka K, Itonaga I, Ikeda S, Iwasaki T and Tsumura H: MicroRNA-93 promotes cell proliferation via targeting of PTEN in Osteosarcoma cells. J Exp Clin Cancer Res 34: 76, 2015.

(i)(3) This work is licensed under a Creative Commons Attribution-NonCommercial-NoDerivatives 4.0 International (CC BY-NC-ND 4.0) License. 